\title{
СТУДЕНТЫ МОСКВЫ И ВОРОНЕЖА О ФАКТОРАХ ПРОФЕССИОНАЛЬНОГО УСПЕХА
}

\author{
Винокурова Н.А., Гудович И.С.
}

В статье анализируются сходства и различия взглядов студентов двух городов - Москвы и Воронежа на предпосылки будущего успеха в профессиональной деятельности. Обсуждаются вопросы о готовности или неготовности работать много и напряженно, о важных факторах, гарантирующих будущую успешность, а также мотивы выбора работы.

DOI: $10.20537 /$ mce2020econ19

Введение. Настоящая работа является частью проекта «Студенты: взгляд в будущее». Основой проекта служат материалы, полученные в результате социологического опроса, проведенного авторами настоящей работы в 2017 г. Анкетирование студентов проходило в воронежских вузах, в том числе на 8 факультетах Воронежского государственного университета, а также в ряде вузов Москвы. Студентам было задано 32 вопроса, которые можно условно разделить на четыре части: будущее России глазами студентов, отношение студентов к российскому образованию, науке и желание работать в этих сферах, представление о качестве жизни, потребностях и предпочтениях в настоящее время и в дальнейшем, вопросы, связанные с выбором будущей профессии.

Основные результаты анализа полученных данных были опубликованы в работах авторов [1-3]. Работа [1] была посвящена выявлению степени готовности студентов принять и поддержать идеологию инновационного, опережающего развития страны, прорыва в шестой технологический уклад. В работе [2] нас интересовали запросы, представления и предпочтения студентов относительно качества жизни как базовой ценностной ориентации. Сравнительному анализу интереса к науке и ученым у студенческой молодежи двух городов - Москвы и Воронежа была посвящена статья [3]. Полученные результаты согласуются с мнением других исследователей, которые отмечают, что «...в период социально-экономических изменений в российском обществе наблюдалась общая динамика возрастания значимости прагматических ценностей для 
личности, достижения успеха делового и в личной жизни, материального благосостояния» [4]. См. также [5, 6].

В настоящей работе обсуждаются сходство и различие во взглядах и предпочтениях студентов двух мегаполисов в отношении успешности в их будущей профессиональной деятельности и выборе работы.

Результаты. Прежде всего, нас интересовало, в каких ситуациях студенты могли бы прилагать большие усилия в работе. В табл. 1 показаны результаты ответов студентов на поставленный вопрос.

Из полученных данных видно, что воронежских студентов, которые готовы были бы работать очень много и напряженно, чтобы стать известным, знаменитым или если результаты работы помогут преодолеть отставание России в современных технологиях, почти в 2 раза больше, чем студентов Москвы. Их также больше (46.2\%), чем москвичей $(40.9 \%)$, если итоги деятельности могут принести много пользы людям. Среди московских студентов больше половины тех, для кого стимулом напряженной работы является хороший заработок и более $75 \%$ москвичей отметили важным для себя наличие интересной творческой работы, в то время как среди воронежских студентов таких меньше половины.

Таблица 1. Распределение ответов на вопрос: «В каком случае Вы лично готовы бы были работать очень много и напряженно? (Отметить не более 2-х вариантов)».

\begin{tabular}{|l|c|c|}
\hline \multicolumn{1}{|c|}{ Варианты ответов } & \multicolumn{2}{|c|}{ Процент ответов } \\
\cline { 2 - 3 } & Москва & Воронеж \\
\hline Чтобы стать известным, знаменитым & 4.6 & 9.6 \\
\hline Чтобы хорошо заработать & 55.4 & 50.0 \\
\hline $\begin{array}{l}\text { Если результаты Вашей деятельности мо- } \\
\text { гут принести много пользы людям }\end{array}$ & 40.9 & 46.2 \\
\hline Если работа интересная и творческая & 75.4 & 48.1 \\
\hline $\begin{array}{l}\text { Если результаты помогут преодолеть от- } \\
\text { ставание России в современных техноло- } \\
\text { гиях }\end{array}$ & 10.9 & 21.2 \\
\hline Другое & 2.0 & 0.0 \\
\hline
\end{tabular}




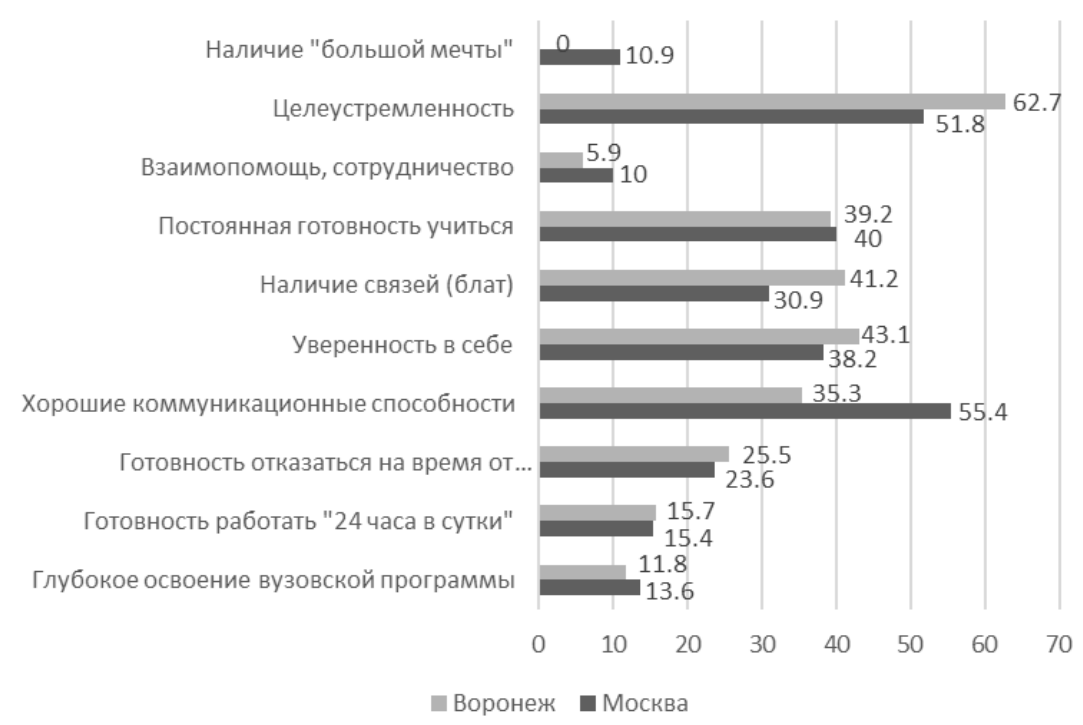

Рис. 1. Распределение ответов на вопрос: «Как Вы считаете, что важно, чтобы добиться успеха в работе после окончания ВУЗа? (Отметить не более 3-х факторов)».

При ответе на вопрос «Как Вы считаете, что важно, чтобы добиться успеха в работе после окончания ВУЗа?» студенты двух городов показали практически одинаковое отношение к таким факторам успешности как глубокое освоение вузовской программы, готовность работать «24 часа в сутки», готовность отказаться на время от больших доходов. При этом только чуть больше десятой части респондентов считает важным преимуществом для успешной работы после окончания ВУЗа глубокое освоение вузовской программы. Это может быть проявлением того, что для значительной части студентов конечной целью обучения в ВУЗе являются не знания, а получение диплома. «Россияне не связывают наличие высшего образования с материальным благополучием человека, но считают его важным для трудоустройства и построения карьеры» [7]. По сравнению с теми, кто ценит полученные в высшем учебном заведении знания, в несколько раз больше тех, кто ценит хорошие коммуникационные способности, уверенность в себе, наличие связей, постоянную готовность учиться. Лидируют в этом отношении «хорошие коммуникацион- 
ные способности» и «целеустремленность». При этом более половины московских участников опроса отметили важность хороших коммуникационных способностей в то время, как только $35.3 \%$ студентов Воронежа посчитали этот фактор как важный. А вот целеустремленность оказалась ценным качеством для большего количества воронежских респондентов: $62.7 \%$ против $51.8 \%$ у москвичей. Интересно отметить, что $41 \%$ воронежцев уверен в важности наличия связей (блата), в то время как среди московских студентов таких оказалось $30.9 \%$, см. рис. 1 .

В следующим поставленном нами вопросе: «Чем Вы будете руководствоваться при выборе работы после окончания ВУЗа?» мы попросили студентов оценить в баллах мотивы выбора, где 7 - самый важный для них мотив, а 1 - совсем не важный. В табл. 2 приведены проценты студентов, которые отметили мотив выбора как самый важный, то есть отметили его числом 7.

Таблица 2. Распределение ответов на вопрос: «Чем Вы будете руководствоваться при выборе работы после окончания ВУЗа?»

\begin{tabular}{|l|c|c|}
\hline \multicolumn{1}{|c|}{ Варианты ответов } & \multicolumn{2}{c|}{ Процент ответов } \\
\cline { 2 - 3 } & Москва & Воронеж \\
\hline Воплотить собственную мечту & 36.4 & 23.5 \\
\hline Развиваться как личность & 40.0 & 31.4 \\
\hline Бросить себе вызов & 7.3 & 11.8 \\
\hline Получить большой личный доход & 32.7 & 33.3 \\
\hline $\begin{array}{l}\text { Обеспечить свою финансовую безопас- } \\
\text { ность }\end{array}$ & 37.3 & 39.2 \\
\hline Построить свой бизнес & 13.6 & 21.6 \\
\hline Продолжить семейную традицию & 5.4 & 0.0 \\
\hline $\begin{array}{l}\text { Быть новатором, на передовой линии но- } \\
\text { вых технологий }\end{array}$ & 7.3 & 5.9 \\
\hline Разработать идею нового продукта & 6.4 & 5.9 \\
\hline Чего-либо достичь, получить признание & 16.4 & 17.6 \\
\hline $\begin{array}{l}\text { Приобрести более высокое положение в } \\
\text { обществе }\end{array}$ & 11.8 & 33.3 \\
\hline Быть собственным начальником & 22.3 & 45.1 \\
\hline Следовать важной социальной миссии & 3.6 & 11.8 \\
\hline $\begin{array}{l}\text { Иметь возможность совмещать работу и } \\
\text { личную жизнь }\end{array}$ & 38.1 & 52.9 \\
\hline
\end{tabular}


Обращает на себя внимание тот факт, что воронежских респондентов, которые отметили, как значительные мотивы — «следовать важной социальной миссии» и «приобрести более высокое положение в обществе», приблизительно в 3 раза больше, чем москвичей. Их в 2 раза больше и среди тех, кто «хочет быть собственным начальником» и больше тех, кто хочет иметь возможность совмещать работу и личную жизнь (52.9\% против 38.1\%). Москвичей заметно больше среди тех, кто хотел бы воплотить собственную мечту (36.4\%), в то время как таких воронежских студентов - $23.5 \%$, а также большее количество московских студентов (40\%) при выборе работы важным мотивом считают возможность развиваться как личность. Воронежцев, считающих эту мотивацию важной, $23.5 \%$ (рис. 2).

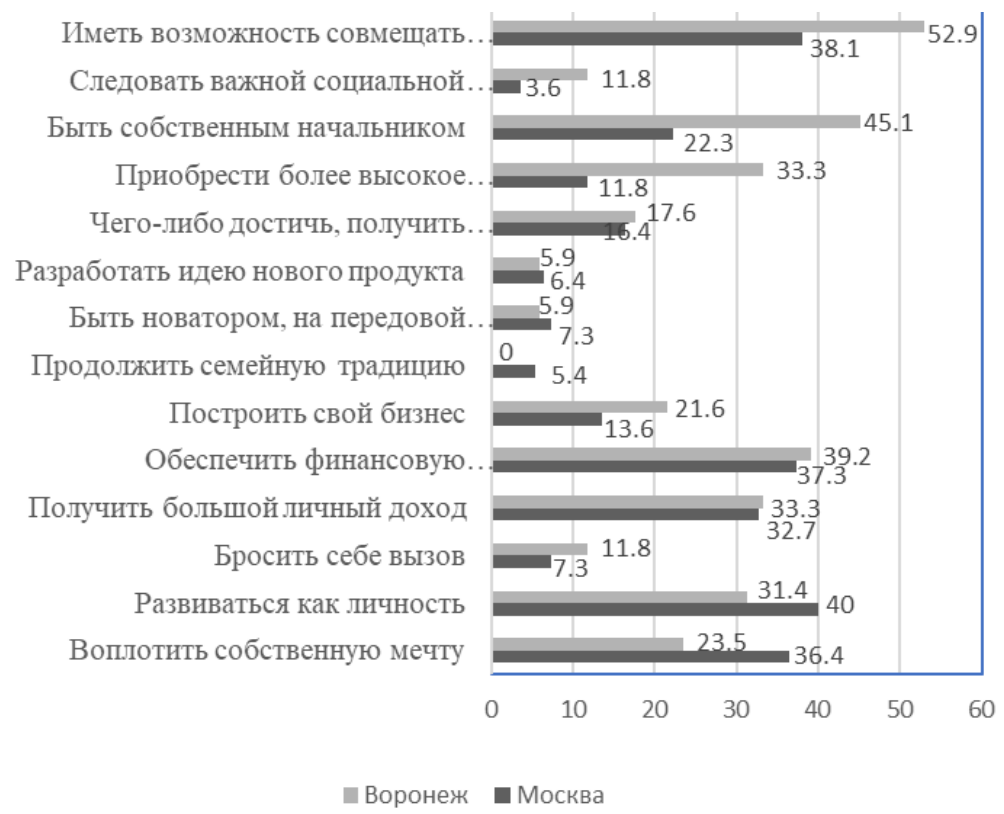

Рис. 2. Распределение ответов на вопрос: «Чем Вы будете руководствоваться при выборе работы после окончания ВУЗа?» 
Распределение ответов на вопрос: «В каком качестве Вы бы предпочли работать?» размещен в табл. 3. Полученные данные подтверждают стремление воронежских студентов в большей степени быть независимыми в экономическом и статусном отношении (быть собственным начальником): основать свое дело хотели бы $65.4 \%$ воронежцев и $50.9 \%$ московских респондентов, а быть наемным сотрудником хотели бы только $21.2 \%$ воронежских студентов и $37.3 \%$ москвичей. Быть фрилансером выразили желание приблизительно 10\% тех и других респондентов.

Таблица 3. Распределение ответов на вопрос: «В каком качестве Вы бы предпочли работать?»

\begin{tabular}{|l|c|c|}
\hline \multirow{2}{*}{ Варианты ответов } & \multicolumn{2}{|c|}{ Процент ответов } \\
\cline { 2 - 3 } & Москва & Воронеж \\
\hline Быть наемным сотрудником & 37.3 & 21.2 \\
\hline Основать свое дело & 50.9 & 65.4 \\
\hline Быть фрилансером & 11.8 & 9.6 \\
\hline
\end{tabular}

Заключение. Исследование подтвердило тот факт, на который авторы указали в работе [3], что московские и воронежские студенты представляют две разные группы молодежи: условно говоря, либеральную и традиционную. Подобную точку зрения по отношению к московской молодежи в целом высказала Грекова О.: «...юные москвичи и юные россияне - две разные социальные группы...Если Москва - отдельное государство, то московская молодежь - отдельная каста. Молодые москвичи инициативны, амбициозны и нелояльны к властям» [5].

По шкале Маслоу москвичи имеют более высокий уровень потребностей: это интересная, творческая работа, стремление развиваться как личность, желание воплотить свою мечту. Москвичей можно назвать индивидуалистами, они в большей степени ориентированы на собственные интересы.

Воронежцы в большей степени социально ориентированы: они готовы работать на благо людей, следовать важной социальной миссии, много работать, если результаты помогут преодолеть отставание России в современных технологиях. Однако, как и москвичи, они стремятся к жизненному комфорту и достойному материальному уровню, демонстрируя относительно большую активность с опорой на целеустремлен- 
ность, желание быть собственным начальником, основать свое дело, занять более высокое положение в обществе.

Следует отметить, что ни те, ни другие в большинстве не имеют в своих планах и желаниях новаторство на передовых линиях новых технологий или разработку идей новых продуктов. Им не интересны достижения, связанные с общественным признанием. Как отмечалось в [6], молодежь сегодня больше всего ценит работу с хорошим заработком без особого напряжения.

\section{СПИСОК ЛИТЕРАТУРЫ}

1. Винокурова Н. А., Гудович И. С., Баклькков А. С. Молодежь как стратегический ресурс будущего развития: ценностные ориентации, планы, мечты // Современная экономика: проблемы и решения. 2017. № 9 (93). С. 14-31.

2. Винокурова Н.А., Гудович И.С. Приоритеты студенчества в отношении качества жизни // Анализ и моделирование экономических и социальных процессов / Математика. Компьютер. Образование: Сб. науч. трудов. М.-Ижевск: НИЦ «Регулярная и хаотическая динамика», 2019. Выпуск 26. C. $108-115$.

3. Винокурова Н.А., Гудович И.С. Москва-Воронеж. Сходство и различия в отношении студентов к науке и ученым. // Современная экономика: проблемы и решения. № 4 (124), 2020. С. 40-53.

4. Журавлева Н. А. Ценностные ориентации личности в изменяющемся российском обществе. // Психол. журн. 2012. Т.33, №1. С. 30-39.

5. Грекова О. Молодежь московская особая // «Московский комсомолеи». URL: https://www.mk.ru/social/2011/06/01/594099-molodezh-moskovskayaosobaya.html

6. Зернов Д.В., Иудин А.А., Овсянников А.А. Социальное самочувствие советского и постсоветского студенчества // Народонаселение. 2015. №1. С. 50-68.

7. Высшее образование: социальный лифт или потерянное время? // ВЦИОМ, аналитический обзор, № 4010, 18.07.2019. URL: https://wciom.ru/news/tematicheskiy_catalog//?cat=141 


\section{MOSCOW AND VORONEZH STUDENTS ABOUT THE FACTORS OF PROFESSIONAL SUCCESS}

\section{Vinokurova N.A., Gudovich I.S.}

The article analyzes the similarities and differences in the views of two cities - Moscow and Voronezh students on the prerequisites for future success in professional activity. The issues of readiness or unwillingness to work hard, important factors guaranteeing future success, as well as motives for choosing job are discussed. 